\title{
Comparison of maximal gastric secretion in smokers and non-smokers with and without duodenal ulcer
}

\author{
P F WHITFIELD AND M HOBSLEY \\ From the Department of Surgical Studies, The Middlesex Hospital and Medical School, London
}

SUMmARY Maximal gastric secretion was induced in 122 control subjects (without peptic ulcer) and 201 preoperative duodenal ulcer patients by intravenous histamine acid phosphate (130 $\mathrm{nmol} / \mathrm{kg} / \mathrm{h})$, and measured as $\mathrm{Vg}(\mathrm{ml} / \mathrm{h})$ and MAO $(\mathrm{mmol} / \mathrm{h})$. In both groups, men secreted more than women, and smokers secreted more than non-smokers. Significant correlations were found between maximal gastric secretion on the one hand, and height, age, and chronic smoking on the other. After standardisation for these factors, including standardisation to zero smoking, the subgroups of the controls no longer differed significantly, as was also the case for the duodenal ulcer patients. Thus, differences in height, age, and smoking habit were sufficient to account for the variation in maximal secretion between individuals in either the control or duodenal ulcer groups. Even after standardisation, however, the duodenal ulcer patients still secreted significantly more than the controls, and therefore, although chronic smoking has been shown to affect maximal gastric secretion, it does not appear to be the sole reason for hypersecretion in duodenal ulcer patients.

We have recently shown ${ }^{1}$ that, in patients with duodenal ulcer, the maximal gastric secretion of smokers was significantly greater than that of nonsmokers, both in men and women. We have also shown a significant positive correlation between the total number of cigarettes smoked over a period of years and maximal gastric secretion. For the women with duodenal ulcer, the difference between the smokers and non-smokers disappeared on correction for height, but it was necessary to include a correction for chronic smoking and age to reach the same result in the men. That is, smoking was associated with raised gastric secretion in men with duodenal ulcer, but not in women. The question now arises as to whether there is any effect of chronic smoking in people without duodenal ulcer, and this study addresses itself to that problem. A preliminary report of this study and the previous one has been published. ${ }^{2}$

\footnotetext{
Methods

SUBJECTS

One hundred and twenty two subjects (79 men and 43

Address for correspondence: Professor M Hobsley, Dept of Surgical Studies Middlesex Hospital, London, W1N 8AA.

Received for publication 1 September 1986.
}

women) who were considered not to have a peptic ulcer, underwent a gastric secretion test. The majority were inpatients of this hospital, the rest being staff or volunteers. The latter and the majority of the inpatients were without gastrointestinal symptoms, and so were considered free of peptic ulcer. Thirty nine of the inpatients had gastrointestinal symptoms, but were found not to have a peptic ulcer by endoscopy or at laparotomy for other conditions. This control group is compared with the 201 patients of the duodenal ulcer group of our previous paper. ${ }^{\prime}$

Maximal gastric secretion was induced by an intravenous infusion of histamine acid phosphate $(130 \mathrm{nmol} / \mathrm{kg} / \mathrm{h}, 0.04 \mathrm{mg} / \mathrm{kg} / \mathrm{h})$. The test included a correction for pyloric loss, using phenol red, and a correction for duodenogastric reflux, using the sodium concentration of the aspirate. Maximal gastric secretion was expressed as the pyloric loss corrected, reflux corrected volume $(\mathrm{Vg}, \mathrm{ml} / \mathrm{h})$ and also as the uncorrected maximal acid output (MAO, $\mathrm{mmol} / \mathrm{h}$ ). Full details of the method of gastric aspiration and the subsequent calculations have been published. ${ }^{3}$ The results are given for $\mathrm{Vg}$ only, the results for MAO being essentially the same. The informed consent of the subjects and of the Clinical 
Investigation Panel (ethics committee) had been obtained.

For each patient, the following were recorded: sex, height, weight, age, number of years of smoking, age of starting to smoke, and the average number of cigarettes smoked per day over the smoking period. Ex-smokers were classified as smokers, and the nonsmokers were all lifelong non-smokers.

Total cigarette consumption for the smokers was expressed as the product of the average number of cigarettes smoked per day and the number of years of smoking, due allowance being given for any period(s) of non-smoking. This measure was square rooted in order to make the distribution symmetrical, and was called the smoking factor (SMF). All the other continuously variable factors were examined for normality, and found to be satisfactory.

Averages were expressed as medians, and their differences tested by the Wilcoxon's rank-sum-test. The medians are given with their $95 \%$ confidence intervals (CI). In Table 1, the numbers of subjects are reduced because accurate smoking data were not obtainable on all subjects.

Multiple regression analysis ${ }^{4}$ was used to estimate the contribution of the various independent factors to maximal gastric secretion. Parallelism and normality were checked using the residuals of the equations, and the slopes, intercepts and correlation coefficients

Table 1 Median values of Vg by sex and smoking habit

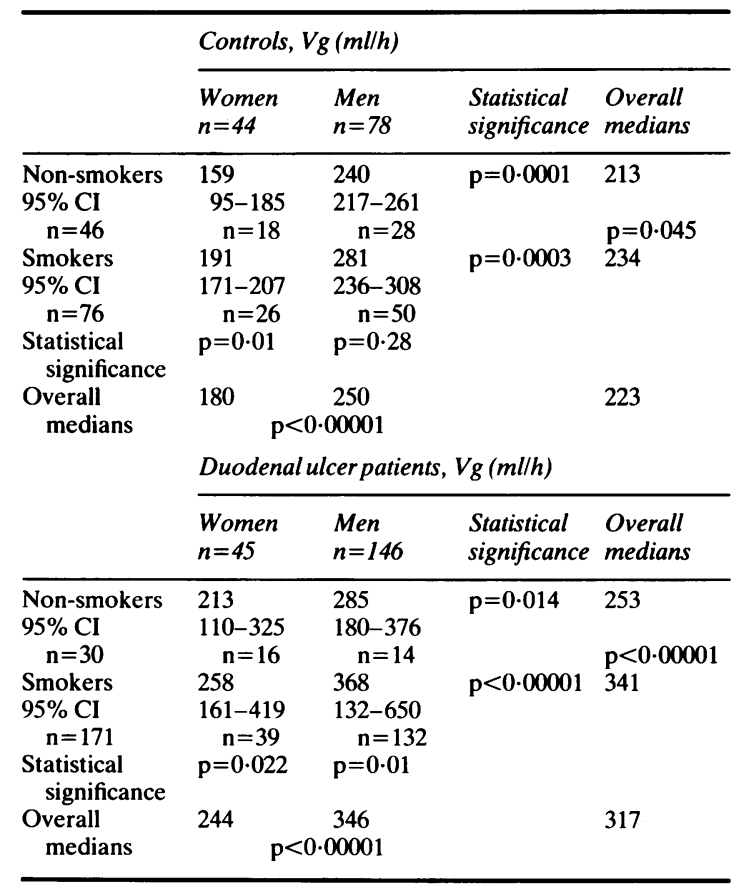

are given, with their statistical significance as assessed by the t-test.

\section{Results}

RAW DATA (TABLE 2)

\section{Controls}

There were significant differences between the sexes within each smoking group, but between the smoking groups there was only a significant difference in the women. Overall, men secreted more than women, and smokers more than non-smokers.

\section{Duodenal ulcer}

There were significant differences between the sexes within each smoking group, and between the smoking groups within each sex. Overall, men secreted more than women, and smokers secreted more than non-smokers, as in the controls.

\section{Comparison of controls and duodenal ulcer}

Each subgroup of the controls differed significantly from it's respective subgroup in the duodenal ulcer group $(p<0 \cdot 01)$, except for the male non-smokers $(p=0.064)$.

\section{REGRESSIONS OF SECRETION AND STATURE} (TABLE 3)

For both controls and the duodenal ulcer group, height was the single best stature related variable, and it effectively excluded other stature-related variables (Eqns 1,2).

\section{Standardisation for stature (Table 3)}

The height equations were used to standardise the maximal secretion data to the mean height $(170 \mathrm{~cm})$ of all the subjects.

\section{Controls}

After height standardisation, women no longer

Table 2 Single and multiple regression equations $(\mathrm{Vg}, \mathrm{ml} / \mathrm{h})$

$$
\begin{aligned}
& 1 \text { Controls : } \mathrm{Vg}=4 \cdot 45^{*} \mathrm{Ht}-519 \\
& \mathrm{r}=0.47 \quad \mathrm{t}=5.98 \quad 4.1 \\
& \mathrm{p}<0.001 \quad 0.001 \\
& 2 \text { Duodenal ulcer: } \mathrm{Vg}=6 \cdot 17^{*} \mathrm{Ht}-706 \\
& \mathrm{r}=0.42 \quad \mathrm{t}=6.52 \quad 4.4 \\
& \mathrm{p}<0.0001 \quad 0.001 \\
& 3 \text { Controls : } \mathrm{Vg}=3 \cdot 28^{*} \mathrm{Ht}-2 \cdot 26^{*} \mathrm{Age}+2 \cdot 16^{*} \mathrm{SMF}-249 \\
& \begin{array}{lllll}
\mathrm{r}=0.54 & \mathrm{t}=3.85 & 3.46 & 3.01 & 1.58
\end{array} \\
& 4 \text { Duodenal ulcer: } \mathrm{Vg}=4 \cdot 0^{*} \mathrm{Ht}+1 \cdot 84^{*} \mathrm{SMF}-356 \cdot 3 \\
& \begin{array}{llll}
\mathrm{r}=0.26 & \mathrm{t}=2.85 & 2.14 & 1.46
\end{array} \\
& \text { (men only) } \quad \mathrm{p}<0.01 \quad 0.05 \quad \mathrm{~ns}
\end{aligned}
$$

Abbreviations: $\mathrm{Ht}$ height, SMF smoking factor, ${ }^{*}$ multiplication symbol 
secreted significantly less than men in either smoking group, and overall, men did not secrete significantly more than women. The secretion of the smokers did not differ significantly from the non-smokers in either sex group. Significance was, however, approached $(p=0.07)$ for the difference between the female nonsmokers and smokers, and smokers as a group secreted significantly more than non-smokers $(p=0.013)$. There was some evidence, therefore, that smoking controls secreted more than non-smoking controls.

\section{Duodenal ulcer}

Male non-smokers and female smokers did not differ significantly from female non-smokers, but male smokers did secrete significantly more $(p<0.02)$ than the other three groups. There was evidence therefore, that the effect of smoking was confined to the men.

\section{Comparison of controls and duodenal ulcer}

After standardisation for height, each subgroup of the controls secreted significantly less $(p<0 \cdot 01)$ than its counterpart in the duodenal ulcer group.

\section{REGRESSIONS OF STATURE AND SMOKING (TABLE 2)}

\section{Controls}

The contribution to maximal gastric secretion in the control group of age, height, weight, sex, smoking group, cigarettes per day, smoking factor, and age of starting smoking were assessed by step wise multiple regression. Three factors emerged as significant: (a) stature - for example, height, weight, or sex; (b) age; and (c) smoking, such as cigarettes per day or smoking factor (Eqn 3). From the analysis of variance table for the multiple regression, $70 \%$ of the variation accounted for by the regression was due to height, $25 \%$ to age, and $5 \%$ chronic smoking. The median years of smoking, age of onset of smoking and cigarettes per day of the control smokers were 22,19 , and 18 respectively; $53 \%$ of the controls were, or had been, habitual smokers.

\section{Duodenal ulcer}

As the effect of smoking appeared to be confined to men, only this group was examined for multiple regressions with stature, age, and smoking, and there was found to be a significant regression of height and smoking factor (Eqn 4). Again, 70\% of the explained variation was due to height, but $30 \%$ to chronic smoking. The median years of smoking, age of starting smoking and cigarettes per day of the smoking male duodenal ulcer patients were 24,19 , and 20 respectively; $90 \%$ of the men were, or had been, habitual smokers.
Table 3 Median values of Vg by sex and smoking habit, after standardisation to height $170 \mathrm{~cm} . \mathrm{Vg}(\mathrm{ml} / \mathrm{h})$

\begin{tabular}{|c|c|c|c|c|}
\hline & \multicolumn{4}{|l|}{ Controls } \\
\hline & $\begin{array}{l}\text { Women } \\
n=44\end{array}$ & $\begin{array}{l}\text { Men } \\
n=78\end{array}$ & $\begin{array}{l}\text { Statistical } \\
\text { significance }\end{array}$ & $\begin{array}{l}\text { Overall } \\
\text { medians }\end{array}$ \\
\hline Non-smokers & 186 & 211 & $\mathrm{p}=0.33$ & 207 \\
\hline $95 \% \mathrm{CI}$ & $137-262$ & $188-239$ & & \\
\hline $\mathrm{n}=46$ & $\mathrm{n}=18$ & $n=28$ & & $\mathrm{p}=0 \cdot 013$ \\
\hline Smokers & 228 & 263 & $p=0 \cdot 36$ & 249 \\
\hline $\begin{array}{r}95 \% \mathrm{CI} \\
n=76\end{array}$ & $\begin{array}{c}212-258 \\
n=26\end{array}$ & $\begin{array}{c}209-281 \\
n=50\end{array}$ & & \\
\hline $\begin{array}{l}\text { Statistical } \\
\text { significance }\end{array}$ & $p=0.07$ & $\mathrm{p}=0 \cdot 14$ & & \\
\hline \multirow{4}{*}{$\begin{array}{l}\text { Overall } \\
\text { medians }\end{array}$} & 222 & 239 & & 225 \\
\hline & \multicolumn{4}{|c|}{$\mathrm{p}=0.20$} \\
\hline & \multicolumn{4}{|c|}{ Duodenal ulcer subjects } \\
\hline & $\begin{array}{l}\text { Women } \\
n=55\end{array}$ & $\begin{array}{l}\text { Men } \\
n=146\end{array}$ & $\begin{array}{l}\text { Statistical } \\
\text { significance }\end{array}$ & $\begin{array}{l}\text { Overall } \\
\text { medians }\end{array}$ \\
\hline Non-smokers & 302 & 296 & \multirow[t]{3}{*}{$p=0.59$} & 300 \\
\hline $95 \% \mathrm{CI}$ & $190-384$ & $182-380$ & & \\
\hline$n=30$ & $n=16$ & $n=14$ & & $p=0 \cdot 009$ \\
\hline Smokers & 318 & 355 & \multirow[t]{5}{*}{$\mathrm{p}=0 \cdot 005$} & 343 \\
\hline $\begin{array}{l}95 \% \mathrm{CI} \\
\mathrm{n}=171\end{array}$ & $\begin{array}{c}211-425 \\
n=39\end{array}$ & $\begin{array}{c}99-610 \\
n=132\end{array}$ & & \\
\hline $\begin{array}{l}\text { Statistical } \\
\text { significance }\end{array}$ & $p=0 \cdot 16$ & $p=0.025$ & & \\
\hline Overall & 313 & 350 & & 328 \\
\hline medians & & & & \\
\hline
\end{tabular}

STANDARDISATION FOR STATURE, AGE AND

SMOKING (TABLE 4)

The regressions of height, age and SMF could be used to standardise the secretion data still further, to a height of $170 \mathrm{~cm}$, an age of 44 , and to zero smoking.

\section{Controls}

The difference between smokers and non-smokers disappeared. All sub-groups (men, women, smokers, non-smokers) became statistically indistinguishable from each other.

\section{Duodenal ulcers}

As in the controls, adding the standardisation for smoking (for the men only) reduced the level of secretion in the smoking males such that the male subgroups no longer differed between themselves, nor did they differ from either of the female subgroups.

\section{COMPARISON OF CONTROLS AND DUODENAL}

ULCERS

After standardisation for height, age and chronic smoking, each subgroup of the duodenal ulcer group still secreted significantly more (about half as much again, $p<0 \cdot 01)$ than its respective subgroup in the controls. 
Table 4 Median values of $V g$ by sex and smoking habit after standardisation to common age and stature, and to zero smoking. $\mathrm{Vg}(\mathrm{ml} / \mathrm{h})$

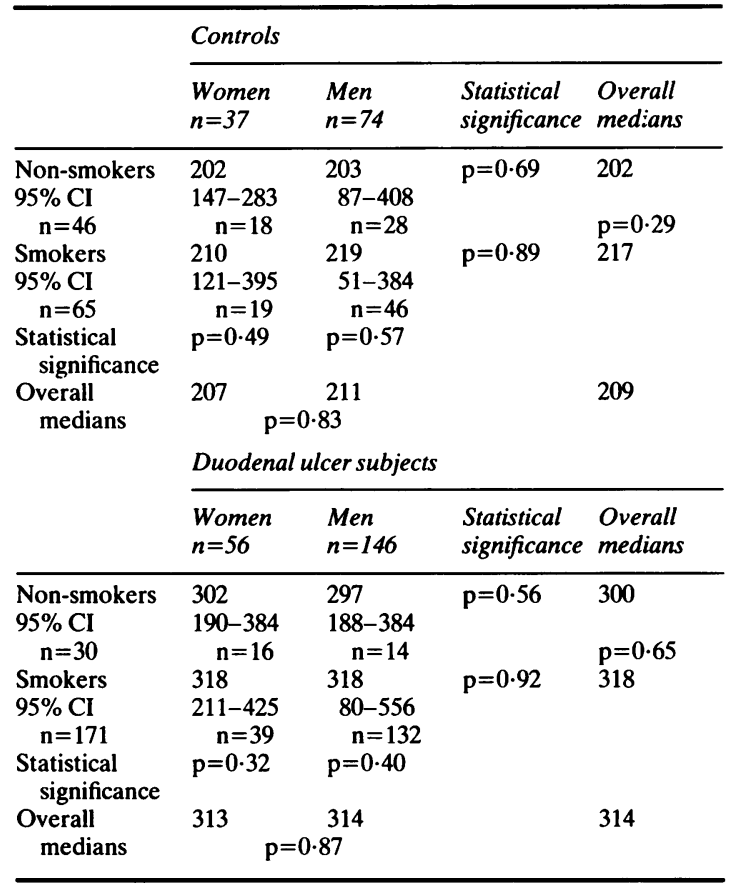

\section{Discussion}

As has previously been found by $\mathrm{us}^{5}$ and other authors, ${ }^{6}$ stature has a positive association with maximal gastric secretion. When our control data were standardised for height, the significant difference between the maximal gastric secretion of men and women disappeared, but this was not so for the duodenal úlcer group.

We had previously found a higher gastric secretion in duodenal ulcer patients who smoked than in those who did not,' and this has been confirmed. ${ }^{7}$ We originally used a multiple regression equation derived from all the patients with duodenal ulcer. On examination of the present results, however, it appears that the smoking effect in this group was confined to the men. Therefore, only the male DU's were used in the multiple regression with smoking.

Further standardisation to zero smoking and for age in both groups removed the significant differences between non-smokers and smokers in the control and DU groups, and between men and women in the DU group.
The overall effect of standardising for height, age and smoking, therefore, was to eliminate the significant differences between the subgroups within each diagnostic group, so making the samples more homogeneous. Thus it appears that simple biological differences (height and age) together with the total dose of cigarettes in those who smoke are sufficient to account for the observed variation between the subgroups.

Standardisation for height, age, and smoking, however, did not diminish the differences between controls and duodenal ulcer subjects, whether of group or subgroup. We can detect in our data no evidence that the effect of smoking in the DU is greater than that in the controls, except for the possible lack of effect in the female DU. This may be a sampling defect, or a true phenomenom, but it was not due to any difference in smoking rate between control and DU female smokers.

Many more of our duodenal ulcer sample, however, were smokers than in the control sample. Although this may be to some extent an artefact of our sampling 'field' (a department of surgery would be most likely to see the more severe cases), smoking has long been suspected as a factor in the aetiology of duodenal ulcer. ${ }^{8}$ Given that chronic smoking raises maximal gastric secretion, it may in some patients be a sufficient cause of the overwhelming of the duodenal defences.

\section{References}

1 Whitfield PF, Hobsley M. Maximal gastric secretion in smokers and non-smokers with duodenal ulcer. Br J Surg 1985; 72: 955-7.

2 Whitfield PF, Hobsley M. Smoking and gastric hypersecretion in duodenal ulcer patients. [Abstract] Gut 1979; 20: A918.

3 Whitfield PF, Hobsley M. A standardised technique for the performance of accurate gastric secretion studies. Agents Actions 1979; 9: 327-32.

4 Draper NR, Smith H. Applied regression analysis. New York: J Wiley, 1966.

5 Hassan MA, Hobsley M. The accurate assessment of maximal gastric secretion in control subjects and patients with duodenal ulcer. Br J Surg 1971; 58: 171-9.

6 Baron JH. Lean body mass, gastric acid, and peptic ulcer. Gut 1969; 10: 637-42.

7 Parente F, Lazzaroni M, Sangaletti O, Baroni S, Biachi Porro G. Cigarette smoking, gastric acid secretion, and serum pepsinogen I. Gut 1985; 26: 1327-32.

8 Ostensen H, Gudmundsen TE, Ostensen PG, Burhol PG, Bonnevie O. Smoking, alcohol, coffee, and familial factors: any associations with peptic ulcer disease? A clinically and radiologically prospective study. Scand $J$ Gastroenterol 1985; 20: 1227-35. 